\title{
BMJ Open Examining the prevalence, correlates and inequalities of undiagnosed hypertension in Nepal: a population- based cross-sectional study
}

\author{
Md. Mehedi Hasan (D) , , ${ }^{1,2}$ Fariha Tasnim, ${ }^{3}$ Md. Tariqujjaman (D) , 4 \\ Sayem Ahmed (D) , ${ }^{5,6,7}$ Anne Cleary (D) , ${ }^{1}$ Abdullah Mamun (D) 1,2
}

To cite: Hasan MM, Tasnim F, Tariqujjaman M, et al. Examining the prevalence, correlates and inequalities of undiagnosed hypertension in Nepal: a population-based cross-sectional study. BMJ Open 2020;10:e037592. doi:10.1136/ bmjopen-2020-037592

- Prepublication history for this paper is available online. To view these files, please visit the journal online (http://dx.doi org/10.1136/bmjopen-2020037592).

Received 09 February 2020 Revised 22 June 2020 Accepted 23 June 2020

Check for updates

(C) Author(s) (or their employer(s)) 2020. Re-use permitted under CC BY-NC. No commercial re-use. See rights and permissions. Published by BMJ.

For numbered affiliations see end of article.

Correspondence to

Md. Mehedi Hasan;

m.m.hasan@uqconnect.edu.au

\section{ABSTRACT}

Objective To examine the prevalence, correlates and sociodemographic inequalities of undiagnosed hypertension in Nepal.

Design This study used cross-sectional 2016

Nepal Demographic and Health Survey (NDHS) data. Undiagnosed patients with hypertension were defined as an NDHS respondent who was diagnosed as hypertensive (systolic blood pressure $\geq 140 \mathrm{mmHg}$ and/or diastolic blood pressure $\geq 90 \mathrm{mmHg}$ ) during the survey, but never took any prescribed anti-hypertensive medicine to lower/ control blood pressure and was never identified as having hypertension by a health professional prior the survey. Multiple binary logistic regression analysis was performed, and Concentration Index was measured.

Setting Nepal.

Participants Adult patients with hypertension.

Results Among 3334 patients with hypertension, 50.4\% remained undiagnosed during the survey in Nepal. Adjusted model reveals that patients who were male, belonged to households other than the highest wealth quintile, and lived in province 4 and province 5 were at higher risk of remaining undiagnosed for hypertension. Patients who were $\geq 65$ years of age and were overweight/obese were at lower risk of remaining undiagnosed for hypertension. The poor-rich gap was 24.6 percentage points ( $Q 1=64.1 \%$ vs $\mathrm{Q} 5=39.6 \%)$ and poor:rich ratio was $1.6(\mathrm{Q} 1 / \mathrm{Q} 5=1.6)$ in the prevalence of undiagnosed hypertension. Undiagnosed hypertension was disproportionately higher among lower socioeconomic status groups (Concentration Index, $\mathrm{C}=-0.18$ ). Inequalities in the prevalence of undiagnosed hypertension further varied across other geographic locations, including place of residence, ecological zones and administrative provinces.

Conclusions Undiagnosed hypertension was highly prevalent in Nepal and there were substantial inequalities by sociodemographics and subnational levels. Increasing awareness, strengthening routine screening to diagnose hypertension at primary health service facilities and enactment of social health insurance policy may help Nepal to prevent and control this burden.

\section{INTRODUCTION}

Hypertension, or raised blood pressure, is a leading cause of global mortality and
Strengths and limitations of this study

- This study determined the prevalence and correlates of undiagnosed hypertension in Nepal using the most updated, population-based, nationally representative data.

- This study measured both wealth-based absolute and relative inequalities in the prevalence of undiagnosed hypertension at national level as well as across place of residence, ecological zones and administrative provinces.

- The cross-sectional nature of the data limits us to measure the causal association between undiagnosed hypertension and the explanatory variables studied.

- The association of some potential behavioural or lifestyle factors such as physical activity, dietary patterns and family history with undiagnosed hypertension remains unmeasured due to lack of available data.

disability, ${ }^{1}$ affecting over one billion people annually. ${ }^{2}$ Hypertension is a directing factor for cardiovascular diseases (CVDs), in particular heart diseases, myocardial infarctions, kidney failure, strokes, disability and premature deaths. ${ }^{23}$ In South-East Asian countries, hypertension affects approximately one in three adults, accounting for nearly 1.5 million deaths annually and contributing to $9.4 \%$ of total deaths. ${ }^{4}$ In South-East Asian countries, more than $50 \%$ of people with hypertension remain undiagnosed. ${ }^{5}$ Nepal has one of the highest prevalence rates of hypertension among South-East Asian countries. ${ }^{6}$

Currently, Nepal is facing an epidemiological transition with an increasing prevalence of hypertension. ${ }^{7}$ A study based on the Nepal Demographic and Health Survey (NDHS) 2016 reported about 20\% of Nepalese adults (aged $\geq 18$ years) had hypertension. ${ }^{8}$ However, other studies have reported that the prevalence of hypertension ranges from $23 \%$ 
to $34 \%$ in Nepal, ${ }^{79-12}$ although not all of these studies are representative of the present day Nepalese population. In 2013, the national non-communicable disease (NCD) risk factor survey showed that while $25.7 \%$ of adults aged 15-69 years had hypertension in Nepal, a further $42.7 \%$ of adults had never measured their blood pressure. ${ }^{13}$ Correct diagnoses of hypertension is prerequisite to the prevention, control and proper treatment of this disease. In addition, failure to diagnose and treat hypertension early may lead to serious health hazards, disability in later life or eventually death. In Nepal, a number of government, non-government and private health facilities are providing health services, such as diagnosis, medication and treatment for hypertension. However, owing to challenges with workforce capacity, resourcing of healthcare facilities and out-of-pocket costs incurred by patients, the current healthcare system in Nepal is not adequately prepared to support the diagnosis, treatment and control of hypertension. ${ }^{14}$

To prevent hypertension, the disease first needs to be diagnosed before any related complications arise. However, there is a lack of evidence about the prevalence of undiagnosed hypertension in Nepal at national and subnational levels. Information on the estimates of undiagnosed hypertension, and its related sociodemographic inequalities, at national and subnational level may assist policy makers in formulating effective strategies for screening, treatment and control as well as prevention of hypertension and associated burdens of disease, particularly among vulnerable groups. As such, we aimed to examine the prevalence, correlates and sociodemographic inequalities of undiagnosed hypertension in Nepal.

\section{METHODS}

\section{Data source}

We used the most updated nationally representative cross-sectional data from NDHS. While the data of Demographic and Health Surveys is managed by Measure Evaluation, the NDHS was conducted from June 2016 to January 2017 by a private research organisation named 'New Era' under the monitoring and supervision of the Ministry of Health, Nepal. To estimate the prevalence of hypertension nationally in Nepal, the NDHS 2016 obtained informed consent from the household head on behalf of all household members of each surveyed household..$^{15}$ For academic and scientific purposes, this anonymous dataset without any identifiers was made available by the ICF International, Maryland, USA ${ }^{15}$ We obtained approval to access and use these data to conduct this study.

\section{Survey procedure and participants}

In 2015, Nepal reformed and restructured municipality boundaries resulting in seven administrative provinces comprising several districts and urban-rural areas with smaller administrative units known as wards. ${ }^{8}$ With comparatively greater household numbers, urban areas were further divided into enumeration areas (EAs). The primary sampling units (PSUs) were wards, for both urban and rural areas. ${ }^{15}$ Because of some changes in administrative areas, Nepal revised the sampling frame of National Population and Housing Census. The 2016 NDHS used this revised sampling frame and applied a multistage survey which was conducted in two and three stages across rural and urban areas, respectively. NDHS selected the PSUs proportionately to the size in the first stage and then the random selection of EAs from the systematic selection of households from each PSU in the second stage. In the third stage, the households were selected by using a stratified cluster sampling technique in urban areas. A detailed description of the methodology is available elsewhere. ${ }^{15} \mathrm{~A}$ total of 11490 households were selected from 383 wards, of which 5520 households from 184 wards were from urban settings and 5970 households from 199 wards were from rural settings. From these households, all the residents aged 15 years or above were eligible for blood pressure measurement. With an overall response rate of $95 \%$, a total of 14823 individuals participated in the survey. This study uses an analytical sample of adults ( $>15$ years) with hypertension $(n=3334)$. Figure 1 illustrates the procedure for selecting the study sample.

\section{Outcome variable}

To measure hypertension, the 2016 NDHS used the UA-767F/FAC (A\&D Medical) automated device to record the blood pressure of the participants. With $5 \mathrm{~min}$ intervals between each measurement, the 2016 NDHS recorded the measurements of blood pressure three times in a sitting position. NDHS considered the last two measures of blood pressure levels and used their mean to detect hypertension. The survey used the guideline of the World Health Organization (WHO) to report a participant as hypertensive. ${ }^{15}$ The WHO guideline has integrated the 2017 guidelines of the American College of Cardiology/ American Society of Hypertension. ${ }^{16}{ }^{17}$ According to the WHO guideline, a participant with systolic blood pressure (SBP) $\geq 140 \mathrm{mmHg}$ or diastolic blood pressure (DBP) $\geq 90 \mathrm{mmHg}$ is diagnosed as a hypertension case. We also considered participants as patients with hypertension if $\mathrm{s} /$ he was previously told by a health professional that they have hypertension or if they were already taking medication to control hypertension. Our outcome variable is undiagnosed hypertension. A patient is considered as undiagnosed for hypertension if, at the time of the survey, $\mathrm{s} /$ he was diagnosed as hypertensive (SBP $\geq 140 \mathrm{mmHg}$ or DBP $\geq 90 \mathrm{mmHg}$ ) but never took any prescribed antihypertensive medicine to lower/control blood pressure and was never told by a health professional that they have hypertension prior the survey. ${ }^{1819}$

\section{Explanatory variables}

This study considered a set of sociodemographic and behavioural characteristics as independent variables. Age (in years), sex, body mass index (BMI) measured 


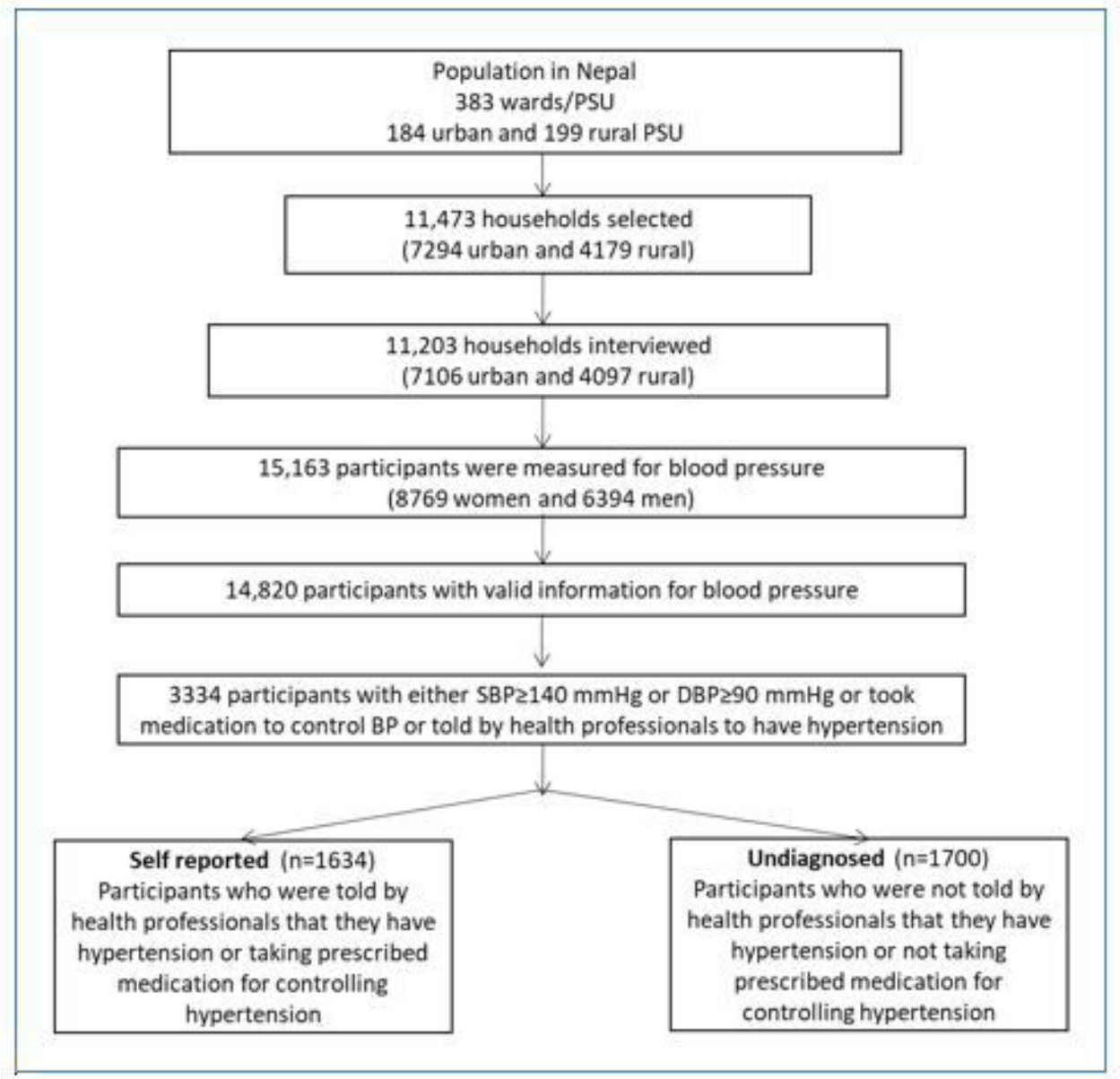

Figure 1 Selection of participants.

through dividing the weight by squared height $\left(\mathrm{kg} / \mathrm{m}^{2}\right)$, education level, household wealth status, place of residence, ecological zone and provinces were considered as sociodemographic characteristics of the patients. Age was categorised as 15-24, 25-34, 35-44, 45-54, $55-64$ and $\geq 65$ years. Sex had two categories, male and female. The BMI was categorised as thin/underweight $\left(\mathrm{BMI}<18.5 \mathrm{~kg} / \mathrm{m}^{2}\right)$, normal $\left(18.5 \mathrm{~kg} / \mathrm{m}^{2} \leq \mathrm{BMI}<25 \mathrm{~kg} /\right.$ $\mathrm{m}^{2}$ ) and overweight/obese $\left(\mathrm{BMI} \geq 25.0 \mathrm{~kg} / \mathrm{m}^{2}\right) .{ }^{20}$ Based on the highest class completed by the respondents, level of education was classified as no education, primary, secondary and higher. NDHS used principal component analysis ${ }^{15}$ to construct the wealth index and order households into five socioeconomic quintiles (poorest, poorer, middle, richer and richest). The place of residence was stratified as urban and rural across all geographic locations. Nepal was ecologically divided in Mountain, Hill and Terai. The seven administrative provinces were identified as province 1 , province 2 , province 3 , province 4 , province 5 , province 6 and province 7 . Three behavioural characteristics of patients, caffeine, tobacco and alcohol consumption, were considered as independent variables, each of which contained dichotomous response of whether or not the patient consumed caffeine, tobacco or alcohol.

\section{Statistical analyses}

Using univariate analysis, we described the prevalence of undiagnosed hypertension and background characteristics of the study patients. The estimates of each of the categorical variables included in this study were reported with numbers, weighted percentages and $95 \%$ confidence interval (CI) of estimates. The weighted prevalence of undiagnosed hypertension was determined across the background characteristics of the study patients from bivariate analysis. Statistical significance was detected by applying $\chi^{2}$ test. Then, we conducted simple and multiple binary logistic regression analyses to examine the correlates of undiagnosed hypertension. The results of the regression analysis were presented in terms of OR with respective $95 \%$ CIs. Variables that were statistically significant in simple logistic regression analysis were entered in the multiple regression model to estimate the adjusted OR (AOR). Notably, the statistical significance was defined at $5 \%$ level ( $p$ value $<0.05$ ). Variance inflation factors to detect multicollinearity among the independent variables were assessed before incorporating them into the multiple regression model. Due to hierarchical structure of NDHS data, we considered the cluster sampling design of the 2016 NDHS to estimate the prevalence and correlates in this study. ${ }^{15} \mathrm{We}$ 
excluded cases with missing values for blood pressure measurements.

Proposed by Wagstaff ${ }^{21}$ to measure the inequality, we estimated the Concentration Index $(\mathrm{C})$, to show the degree and direction of wealth-based inequality in undiagnosed hypertension prevalence. For the purpose of calculating $\mathrm{C}$, the households were ranked from the poorest to the richest according to their socioeconomic characteristics. We plotted a concentration curve to portray the distribution of undiagnosed hypertension. The Y-axis of the concentration curve represents the cumulative proportion of undiagnosed hypertension and the X-axis represents the cumulative proportions of the population across wealth quintiles. When the concentration curve coincides with the diagonal, the prevalence of undiagnosed hypertension is treated as equally distributed across socioeconomic groups. In contrast, the concentration curve typically deviates from the diagonal if there exists inequalities in the prevalence of undiagnosed hypertension. The $\mathrm{C}$ is defined as twice the area between the concentration curve and the diagonal. ${ }^{22-24}$ The index value can range between -1 and +1 , a positive value implies the prevalence of undiagnosed hypertension is more concentrated among higher socioeconomic status groups and a negative value implies the prevalence is more concentrated among lower socioeconomic status groups. ${ }^{2325}$ We repeated the estimation of $\mathrm{C}$ across other geographical locations such as place of residence, ecological zones and provinces to detect the group of patients with the highest severity of socioeconomic inequalities in the prevalence of undiagnosed hypertension. STATA (version V.13) was used to perform all the analyses. ${ }^{26}$

\section{Patient and public involvement}

Patients and public were not involved in developing the research questions, measuring outcome and designing the study. Information of the participants was anonymous.

\section{RESULTS}

\section{General characteristics of the study patients}

Table 1 shows the general characteristics of the study patients. Among the patients studied, the average age of patients was 49.8 years $(95 \%$ CI $49.1,50.5)$ with the lowest percentage of patients in the 15-24 years age group $(6.6 \%)$ and the highest percentage of patients in the 45-54 years age group (20.9\%). The sample was balanced among male $(49.5 \%)$ and female $(50.5 \%)$ patients. Nearly half of the patients were normal in terms of their BMI, while more than one-third of the patients were overweight/obese. Two-thirds of the patients resided in urban areas $(64.9 \%)$. The educational status of the patients was poor with nearly half of the patients having no education, while $24.1 \%$ and $11.5 \%$ had secondary and higher education, respectively. The highest number of patients belonged to the richest wealth quintile $(28.3 \%)$ and the lowest number of patients belonged to the poorest wealth quintile $(15.5 \%)$. Also, the highest number of patients were from province $3(26.0 \%)$ followed by province 5 $(17.8 \%)$ and province $1(17.0 \%)$. Only $5.6 \%$ of patients were from the mountain ecological zone.

\section{Prevalence of undiagnosed hypertension}

Of the 3334 patients who had hypertension during the survey, more than half of them were detected as remaining undiagnosed $(50.4 \%)$. The prevalence of undiagnosed hypertension among the patients varied across their age ( $p$ - value $<0.001)$, sex ( $p$ - value $<0.001)$, BMI (p- value $<0.001)$, wealth quintile ( $p$ - value $<0.001$ ) and place of residence ( $\mathrm{p}$ - value $<0.01$ ). The prevalence of undiagnosed hypertension was higher among younger patients (15-24 years age group) and steadily decreased with the increase of age. The prevalence of undiagnosed hypertension was higher among male patients $(54.2 \%)$ compared with female patients $(46.7 \%)$. Compared with patients with normal BMI, the prevalence of undiagnosed hypertension was higher among patients with lower BMI (57.8\%) and lower among overweight/obese patients $(44.4 \%)$. Compared with patients of the richest wealth quintile $(39.6 \%)$, the prevalence of undiagnosed hypertension was higher among patients of the poorest $(64.1 \%)$ and poorer $(55.8 \%)$ quintiles. The rate of undiagnosed hypertension was higher among rural patients (55.2\%) compared with urban $(47.8 \%)$. No educational, ecological and provincial variations in the prevalence of undiagnosed hypertension were observed (table 1).

\section{Correlates of undiagnosed hypertension}

We found that age, sex, BMI, wealth quintile, place of residence and province were significantly associated with the prevalence of undiagnosed hypertension among patients with hypertension in unadjusted logistic regression analysis (see online supplemental table 1).

Figure 2 represents the results of multiple logistic regression analysis. The multiple binary logistic regression model showed that age, sex, BMI, wealth quintile and province had a significant association with undiagnosed hypertension. Elderly patients ( $\geq 65$ years of age) had a lower likelihood of being undiagnosed for hypertension than patients aged $15-24$ years $(\mathrm{AOR}=0.65,95 \% \mathrm{CI} 0.48$, $0.91)$. Male patients were 1.29 times more likely than female patients to remain undiagnosed for hypertension (AOR $=1.29,95 \%$ CI 1.11, 1.51). Compared with patients with normal BMI, overweight/obese patients $(\mathrm{AOR}=0.80$, $95 \%$ CI $0.69,0.93$ ) were less likely to have undiagnosed hypertension.

We found wealth quintiles as potential correlates of undiagnosed hypertension. The risk of remaining undiagnosed for hypertension increased with decreasing socioeconomic status. Likelihood of having undiagnosed hypertension was greater among poorer socioeconomic status patients compared with higher socioeconomic quintiles. Patients of poorest and poorer wealth quintiles were $2.49(\mathrm{AOR}=2.49 ; 95 \% \mathrm{CI} 1.90,3.30)$ and 1.67 (AOR $=1.67 ; 95 \%$ CI 1.29, 2.16) times more likely to have 


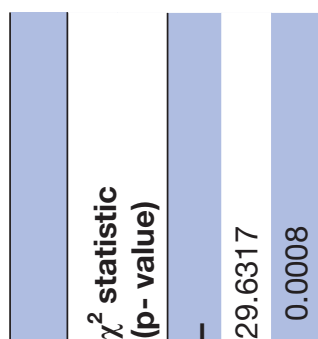

๑. ๑

กิ่ ஜ்

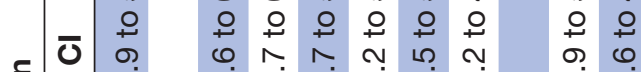

을

ำ

$\begin{array}{lllllllllll} & 0 & 0 & \infty & 0 & m & a & n\end{array}$

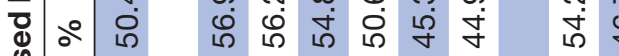

ำ

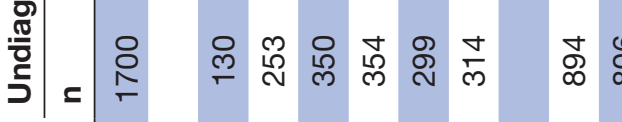

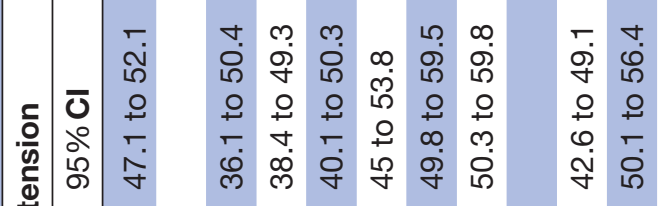

产

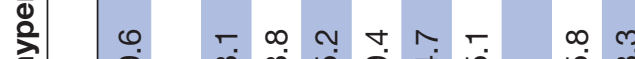

产

马్

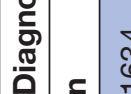

ヘิ

유 ले ले लै

文

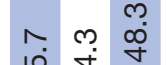

เก

$+\circ \stackrel{\circ}{+} 10$

는
กิ

ֻ
낭

8ं

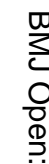

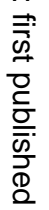

$\infty_{\infty}^{\infty}$

$\vec{o}$

$\overrightarrow{\vec{\omega}}$

응.

莡

嵌

○

$\overrightarrow{0}$

$\frac{0}{\stackrel{0}{0}}$

设

ㅁํㅇ

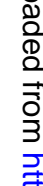

余

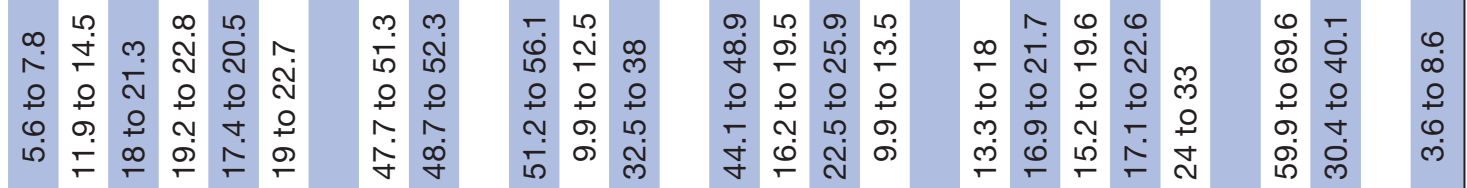

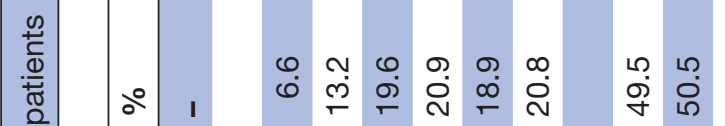

ஸिं

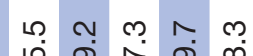

๑ேं மூ

เீ

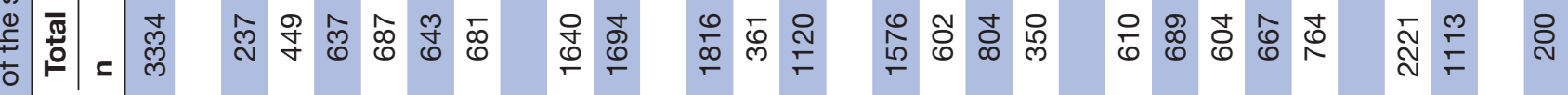

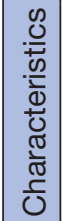

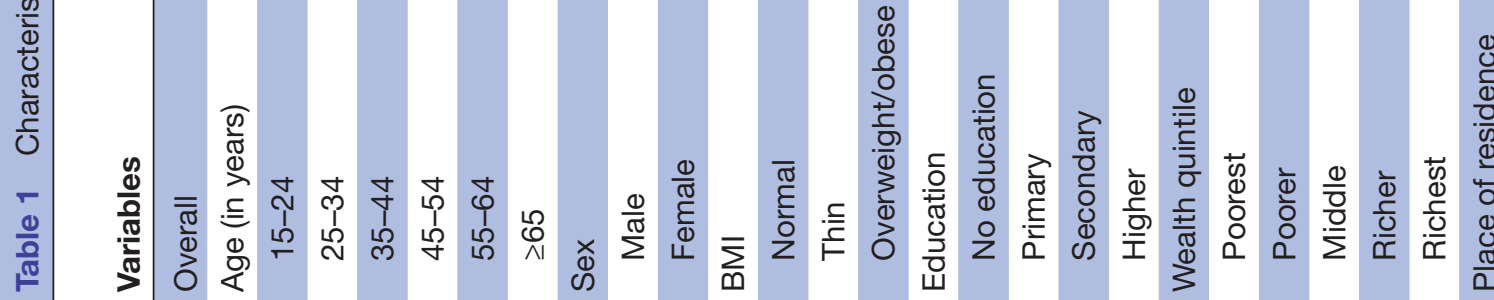

$\Phi$
$\mathbb{D}_{0}^{\circ}$
$\stackrel{0}{0}$

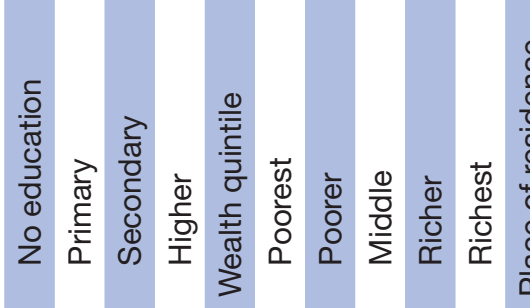

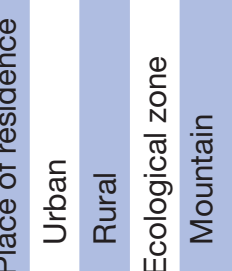




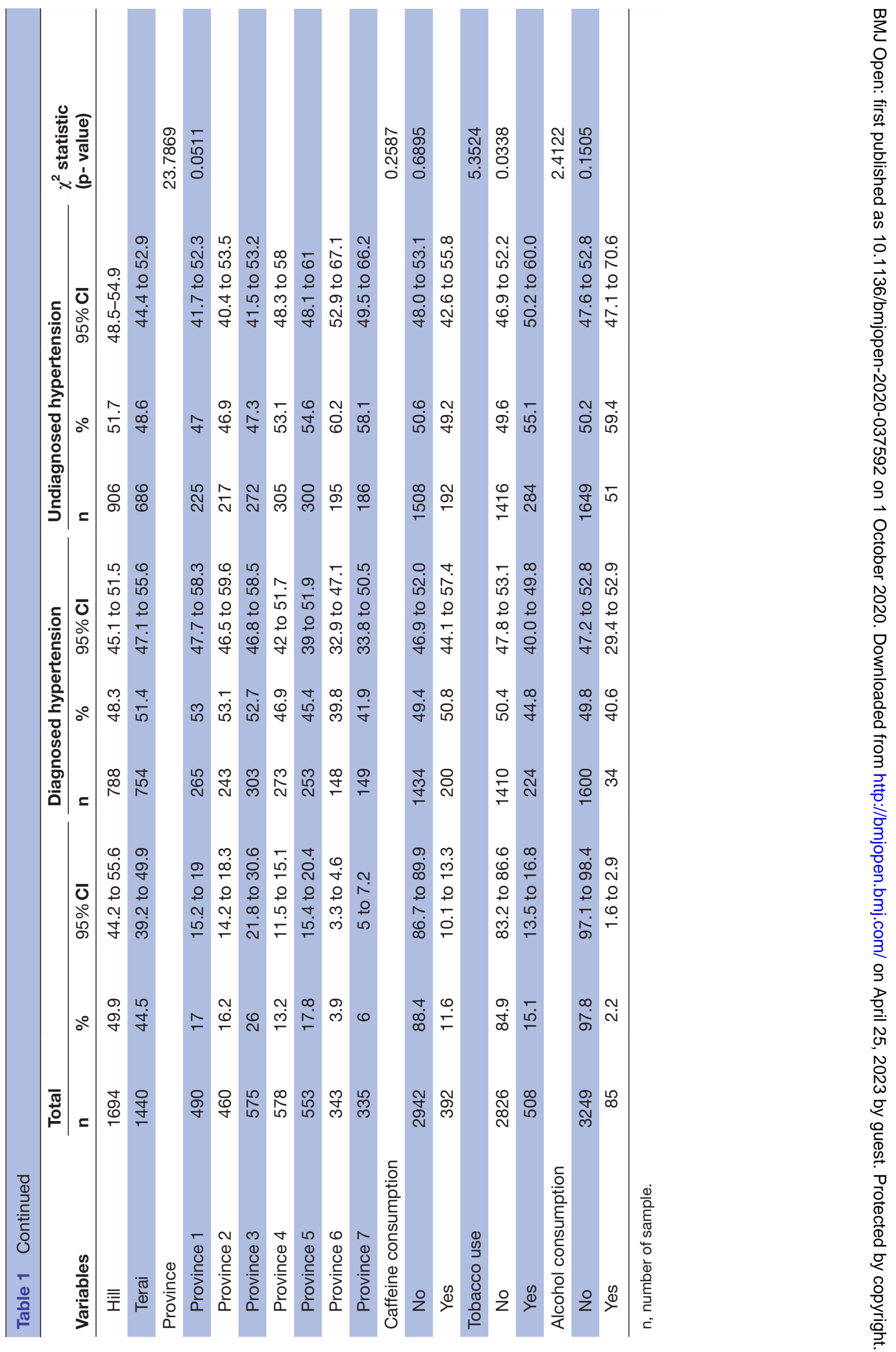




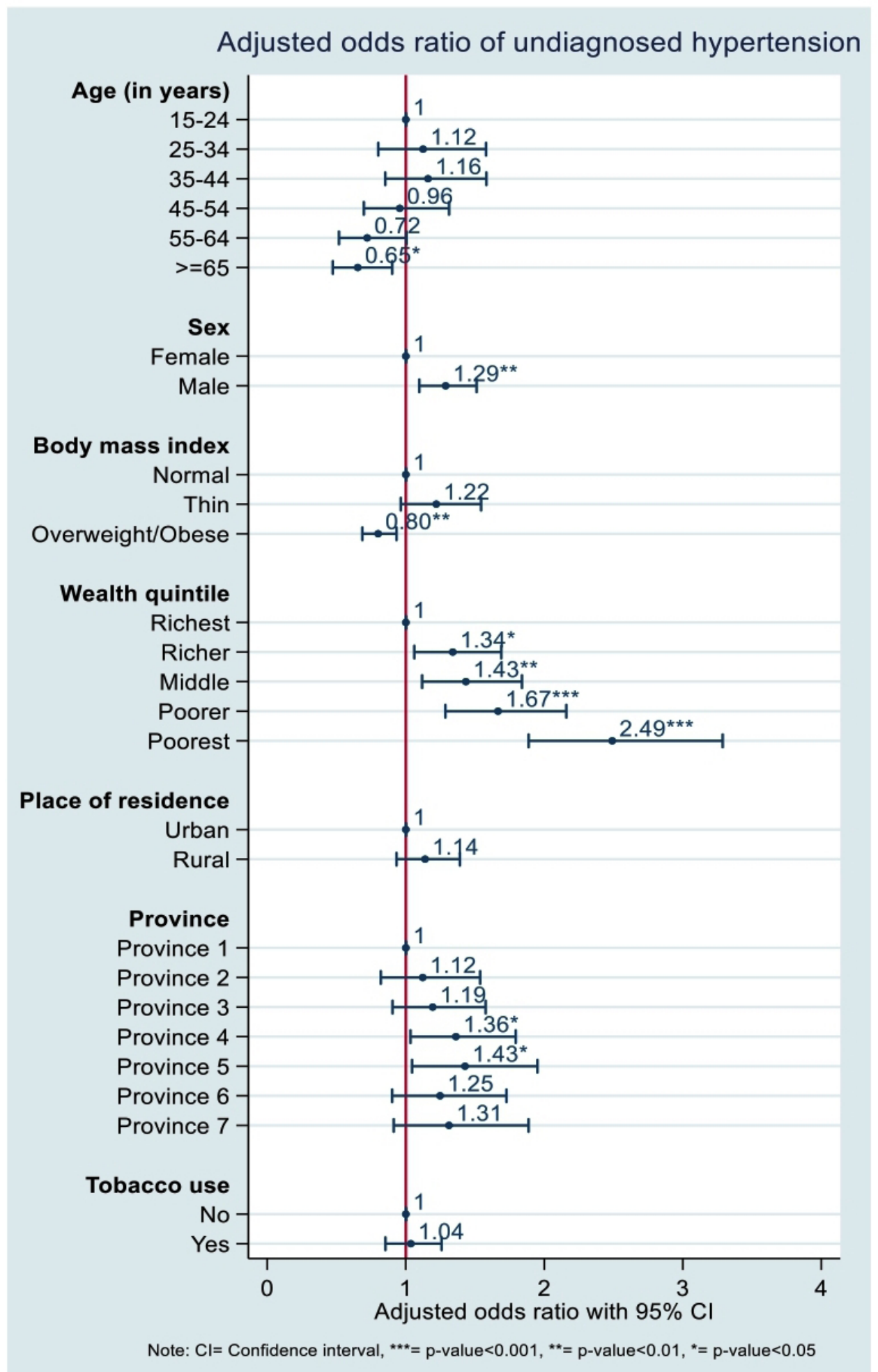

Figure 2 Correlates of undiagnosed hypertension among patients with hypertension in Nepal, 2016.

an undiagnosed hypertension condition than patients of the wealthiest quintile.

Moreover, significant provincial variation was evident in the prevalence of undiagnosed hypertension among hypertensive patients. Patients of province $4(\mathrm{AOR}=1.36$, $95 \% \mathrm{CI} 1.04,1.79)$ and province $5(\mathrm{AOR}=1.43,95 \% \mathrm{CI}$ $1.05,1.95)$ were more likely to have undiagnosed hypertension than patients of province 1 .
Socioeconomic inequalities in undiagnosed hypertension Figure 3 depicts the inequalities in the prevalence of undiagnosed hypertension among hypertensive patients. The difference in the distribution of undiagnosed hypertension was $24.6 \%$ between the lowest wealth quintile (Q1) and highest wealth quintile (Q5), meaning that the prevalence of undiagnosed hypertension was greater by 24.6 percentage points among the poorest patients. The 


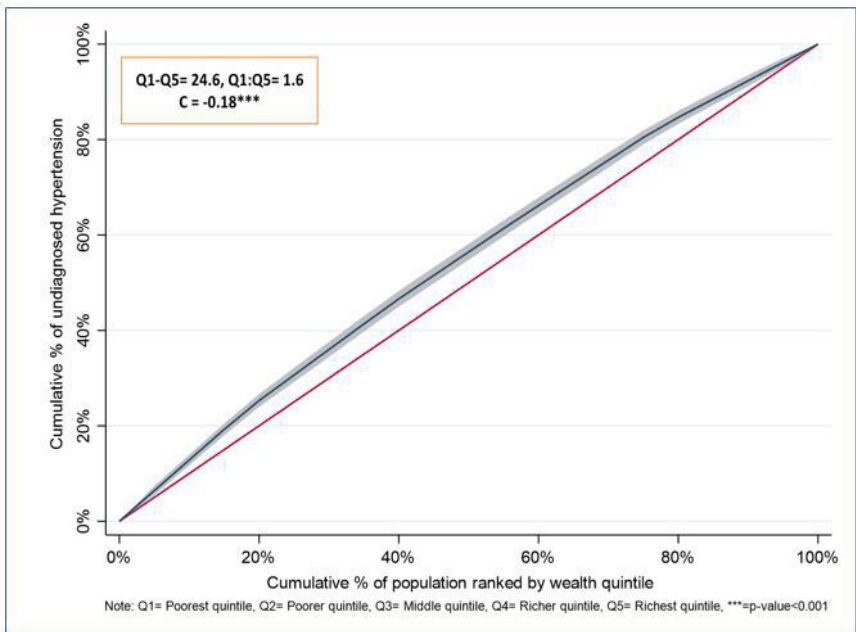

Figure 3 Concentration curve to measure the wealth-based inequality in the prevalence of undiagnosed hypertension among patients with hypertension in Nepal, 2016.

relative measure of inequality in terms of poor $(\mathrm{Q} 1)$ : rich (Q5) ratio was 1.6 for the prevalence of undiagnosed hypertension among patients, depicting that the prevalence of undiagnosed hypertension was 1.6 times higher among the poorest than the richest patients. We found negative value of the Concentration Index $(C=-0.18)$, which suggests that the prevalence of undiagnosed hypertension among patients with hypertension was disproportionately distributed among lower socioeconomic status groups.

In addition, patients living in mountain areas and in province 7 had large gaps in the prevalence of undiagnosed hypertension (figure 4). The higher Q1:Q5 ratio was observed among those who had large Q1-Q5 gaps in the prevalence of undiagnosed hypertension across different geographic locations. We found large negative values of $\mathrm{C}$ among those who had higher Q1-Q5 gaps and Q1:Q5 ratio for the prevalence of undiagnosed hypertension. See figure 4 for details.

\section{DISCUSSION}

Globally, to date, few studies have been conducted on undiagnosed hypertension. For the first time, this study estimated the prevalence of undiagnosed hypertension in Nepal as $50.4 \%$ of respondents who tested positive for hypertension in the 2016 NDHS. In addition, this study identified the risk factors and inequalities associated with undiagnosed hypertension in Nepal. The high prevalence of undiagnosed hypertension identified in this study may be due to people's lack of awareness and willingness to partake in regular health check-ups in the absence of health issues, coupled with accessibility barriers to screening services. ${ }^{27}$ Lack of knowledge, attitudes and behaviours that promote healthy lifestyles as preventive measures to NCDs may also act as a driver of undiagnosed

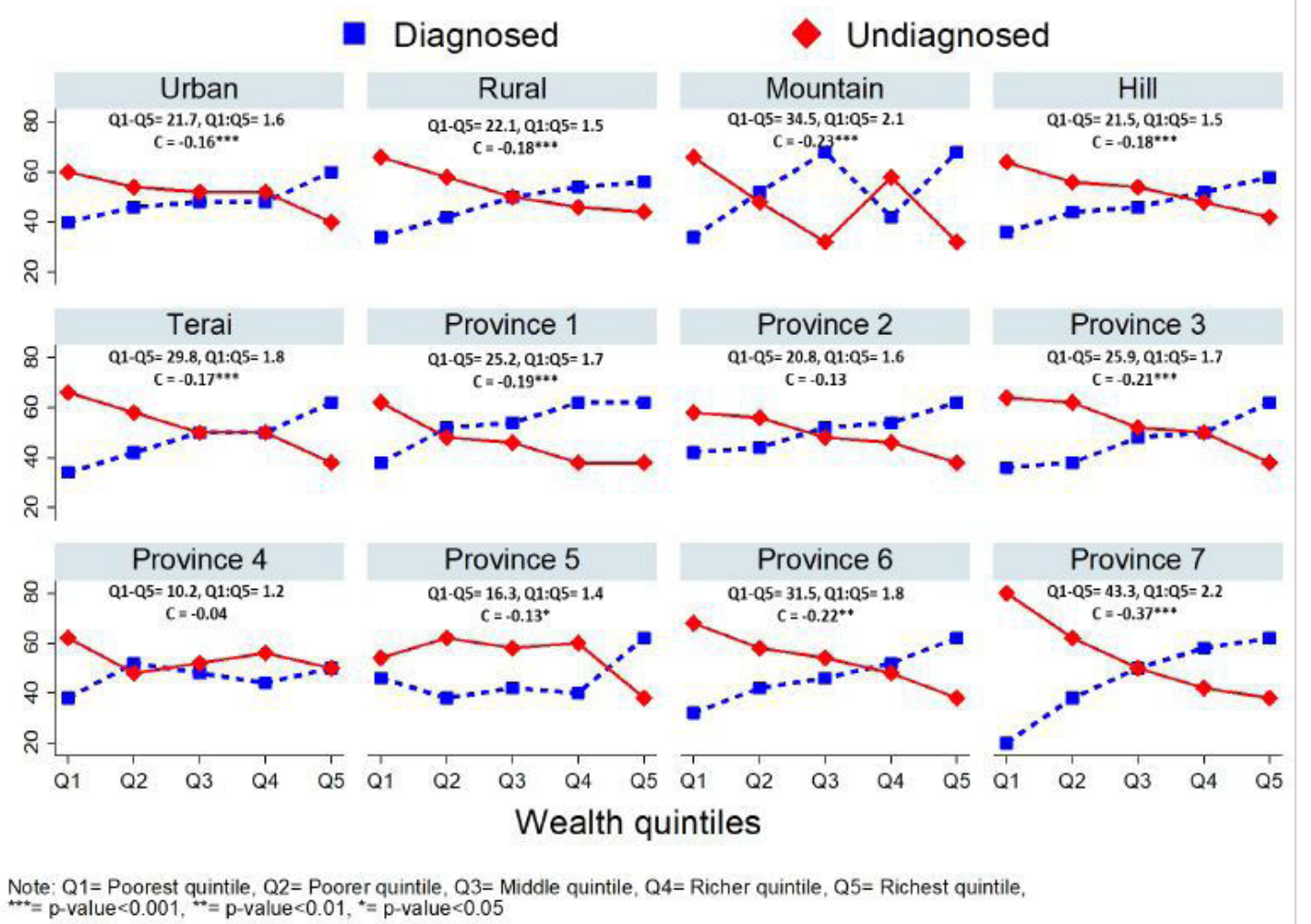

Figure 4 Socioeconomic inequalities in the prevalence of undiagnosed hypertension among patients with hypertension across geographical locations in Nepal, 2016. 
hypertension. ${ }^{27-29}$ Community-based awareness raising of changing lifestyles to address the burden of NCDs might be effective in reducing this gap. ${ }^{30}$

Several studies have reported higher risks of hypertension among people who are older in age, male, urban dwellers, have higher education level, regularly consume tobacco and/or alcohol, or are overweight. ${ }^{682829} \mathrm{We}$ found that patients aged $\geq 65$ yearsand who were overweight/obese were at lower risk of remaining undiagnosed from hypertension. Our findings depicted a greater proportion of undiagnosed hypertensive patients among those who were young and those with lower BMI. Young or underweight people may be less conscious about their health status as they might have the misconception that they are less likely to suffer from NCDs. ${ }^{31}$ In addition, people from lower socioeconomic status groups in Nepal tend to have less knowledge and awareness about health hazards, typically have poorer access to services for screening diseases and lack the capacity to afford treatment costs for diseases. ${ }^{28}$ This may contribute to the disproportionate occurrence of undiagnosed hypertension among lower socioeconomic status groups in Nepal.

Similar to risk factors of hypertension, undiagnosed hypertension was also more prevalent among males and tobacco users. ${ }^{629}$ The higher rate of undiagnosed hypertension among males might be due to their lack of awareness and lower treatment rates than females. ${ }^{32}$ Smoking, a main source of using tobacco, is well recognised to be associated with an increased risk of hypertension in many settings, including Nepal. ${ }^{33}{ }^{34}$ However, there is a lack of evidence to determine the extent to which tobacco use is related to patients remaining undiagnosed for hypertension. Our findings demonstrate that, in Nepal, factors other than tobacco use played independent roles in predicting the rate of undiagnosed hypertension. While differences in lifestyle practices between males and females in Nepal may be a key factor behind different exposures, further research is needed to identify the actual risk factors. ${ }^{29}$

Undiagnosed hypertension may lead to adverse health consequences, including organ damage. ${ }^{35}$ The WHO, denoting hypertension as a silent killer, stated that the prevalence of hypertension is higher in low-income and middle-income countries compared with developed and high-income countries. ${ }^{3}$ Our results support this claim and also align with findings from Bangladesh and subSaharan Africa. ${ }^{19} 3637$ Despite being neighbouring countries, the prevalence of undiagnosed hypertension from this study (approximately 50\%) is much higher than that of China. ${ }^{38}$ For example, recent evidence shows that the prevalence of undiagnosed hypertension in China is $28.8 \% .^{39}$ The reason behind this difference might be due to the differences in the age of study participants. Our study assessed participants of age 15 years or older in Nepal, while the Chinese study included older participants (over 45 years) who may be more aware of health conditions and more likely to visit doctors for regular health check-ups. Findings from studies conducted in countries with more developed healthcare systems and advanced screening processes such as Japan, Korea, England, Ireland, Egypt, Brazil and the USA were also found to have lower levels of undiagnosed hypertension than Nepal as found in this study. ${ }^{40-46}$ The prevalence of undiagnosed hypertension in Nepal is relatively closer with that of Bangladesh. ${ }^{19}$ This might be due to the less advanced healthcare systems of these two countries with both countries displaying low Health Care Index values. ${ }^{38}$

In Nepal, despite the detection of risk factors ${ }^{629}$ and inequalities ${ }^{28}$ the prevalence of hypertension has been well investigated nationally, resulting in the implementation of new policies to mitigate the rising number of patients with hypertension. ${ }^{47}$ However, these policy reform efforts will fail to effectively achieve intended hypertension reduction targets if patients remain undiagnosed, undetected and untreated. It is necessary to identify whether the unequal distribution of undiagnosed hypertension exists among patients with hypertension across different socioeconomic groups. Such information will aid in setting priorities and effective allocation of resources. Our study reveals the existence of inequalities in the distribution of undiagnosed hypertension due to economic status. Lower socioeconomic status groups experienced a higher prevalence of undiagnosed hypertension compared with higher socioeconomic groups and a greater degree of wealth-based inequality was concentrated among the poorest. These inequalities were more prevalent among patients living in different geographical locations including place of residence, ecological zones and administrative provinces. Such disparities may be owing to greater awareness of health issues and more utilisation of healthcare services among higher socioeconomic groups. ${ }^{28}$ Such inequality might increase the catastrophic health spending, given the rise of catastrophic household expenditure due to NCDs in Nepal. ${ }^{148}$ Public health strategies might reduce this gap by concentrating more on implementing social health insurance policies which are equitable for all. ${ }^{40} 48$ In this respect, policymakers could take into consideration the disparities in the distribution of undiagnosed hypertension found in this study.

Several initiatives have been taken to control hypertension in Nepal. To address the burden of CVD, the WHO and partners launched an initiative called 'Global Hearts' in $2016 .{ }^{49}$ This initiative took a comprehensive approach to help countries in scaling-up affordable and adaptable measures to improve the capacity of healthcare services to better detect and treat people at risk of or suffering from CVD. This initiative comprises three packages: SHAKE, HEARTS and MPOWER. The package 'HEARTS' provides tools to incorporate CVD management best practices at the primary healthcare level to reduce CVD risk factors such as hypertension and high blood cholesterol. Like many low to middle incomes countries, Nepal has adapted the Global Hearts initiative to address CVD. In addition, the Community-Based Management of Hypertension in Nepal is a community-based cost-effective intervention 
with demonstrated success in reducing hypertension in Nepal. ${ }^{50}$ However, for designing future programmes or interventions for the prevention of hypertension in Nepal, our findings highlight the importance of considering undiagnosed hypertensive cases and the uneven distribution of such cases across a spectrum of sociodemographic characteristics.

Failing to diagnose and detect hypertension among vulnerable populations will have detrimental health outcomes for any nation. This study, for the first time at a national level, sheds light on the prevalence of undiagnosed hypertension in Nepal. The NDHS 2016, through the incorporation of biomarker tests, bears evidence that a substantial proportion of individuals are suffering from blood pressure abnormalities. This emphasises the need for conducting routine screening for hypertension that ensures access by lower socioeconomic groups and at risk populations. A routine surveillance system with technology-based screening can aid in tracing disease incidence including among people at risk of being undiagnosed.$^{52}$ Our study findings will help inform and initiate policies and programmes that capture the highest domain of vulnerable populations and bring them under routine surveillance at the community level with optimal cost.

\section{Strengths and limitations}

We used the most updated, nationally representative, cross-sectional data to determine the prevalence, correlates and inequalities of undiagnosed hypertension in Nepal. We considered the complex survey design in our methods and captured variations. However, there may be residuals and unmeasured behavioural or lifestyle factors potentially relevant to undiagnosed hypertension, for example, physical activity, dietary patterns and family history of hypertension, that were not explored in this study. Since our data were cross-sectional, the relationship between undiagnosed hypertension and confounders were probabilistic rather than causal. However, identification of potential correlates through using OR is widely acceptable. This study measured both absolute and relative inequalities in the prevalence of undiagnosed hypertension at national level as well as across place of residence, ecological zones and administrative provinces to further guide policy/decision makers for better allocation of resources to reduce hypertension rates.

\section{CONCLUSIONS}

For the first time on a national level in Nepal, this study estimates the prevalence of undiagnosed hypertension as $50.4 \%$ of respondents who tested positive for hypertension in the NDHS. Furthermore, our results show that the prevalence of undiagnosed hypertension is disproportionately higher among lower socioeconomic status groups in Nepal. Our results suggest that efforts should be made to improve the knowledge, attitudes and practices of people around hypertension, particularly among those who are young, slender, poor and male, given their higher risk of being undiagnosed. Routine screening and strengthening the diagnosis of hypertension in the primary level of healthcare service facilities may help Nepal in reducing cases with undiagnosed hypertension. Moreover, identification of inequalities among different risk groups will be beneficial in achieving the universal health coverage target of the United Nations Sustainable Development Goals (Goal 3.8.1). Social health insurance policies under an integrated national NCD policy should be properly enacted to ensure socioeconomically disadvantaged populations are adequately covered under the scheme for the prevention and control of hypertension.

\section{Author affiliations}

${ }^{1}$ Institute for Social Science Research, The University of Queensland, Indooroopilly, Queensland, Australia

${ }^{2}$ ARC Centre of Excellence for Children and Families over the Life Course (The Life Course Centre), The University of Queensland, Indooroopilly, Queensland, Australia ${ }^{3}$ Maternal and Child Health Dlvision, International Centre for Diarrhoeal Disease Research, Bangladesh (icddr,b), Dhaka, Bangladesh

${ }^{4}$ Nutrition and Clinical Services Division, International Centre for Diarrhoeal Disease Research, Bangladesh (icddr,b), Dhaka, Bangladesh

${ }^{5}$ Health Systems and Population Studies Division, International Centre for Diarrhoeal Disease Research, Bangladesh (icddr,b), Dhaka, Bangladesh

${ }^{6}$ Department of Tropical Disease Biology, Liverpool School of Tropical Medicine, Liverpool, UK

${ }^{7}$ Health Economics and Policy Research Group, Department of Learning, Informatics, Management and Ethics, Karolinska Institutet, Stockholm, Sweden

Acknowledgements We acknowledge the MEASURE DHS for providing access to NDHS 2016 datasets. International Centre for Diarrhoeal Disease Research, Bangladesh (icddr,b) is thankful to the Governments of Bangladesh, Canada, Sweden, and the UK for providing core/unrestricted support. MMH acknowledges the financial assistance from the University of Queensland and the Commonwealth Government of Australia to undertake his PhD.

Contributors MMH, SA and AM conceptualised the study. MMH contributed to data acquisition, data analysis, interpretation of the findings and drafting the manuscript. FT, MT and AC helped to interpret the results and contributed to drafting the manuscript. AM, AC and SA critically reviewed the analysis and final version of the manuscript. All authors made a thorough review of the final draft. All authors read and approved the final manuscript for publication.

Funding The authors have not declared a specific grant for this research from any funding agency in the public, commercial or not-for-profit sectors.

Competing interests None declared.

Patient and public involvement Patients and/or the public were not involved in the design, or conduct, or reporting, or dissemination plans of this research.

Patient consent for publication Not required.

Ethics approval The NDHS survey methodology and questionnaire were reviewed and approved by the ethical review board of Nepal Research Council and ICF Institutional. NDHS obtained informed consent from the respondents before conducting the survey. Therefore, separate ethical approval was not required for this study and we are using publicly available de-identified data.

Provenance and peer review Not commissioned; externally peer reviewed.

Data availability statement Data are available in a public, open access repository. All data related to the study are included in the manuscript.

Open access This is an open access article distributed in accordance with the Creative Commons Attribution Non Commercial (CC BY-NC 4.0) license, which permits others to distribute, remix, adapt, build upon this work non-commercially, and license their derivative works on different terms, provided the original work is properly cited, appropriate credit is given, any changes made indicated, and the use is non-commercial. See: http://creativecommons.org/licenses/by-nc/4.0/.

\section{ORCID iDs}


Md. Mehedi Hasan http://orcid.org/0000-0001-7801-0506

Md. Tariqujjaman http://orcid.org/0000-0002-0172-9501

Sayem Ahmed http://orcid.org/0000-0001-9499-1500

Anne Cleary http://orcid.org/0000-00001-8289-7373

Abdullah Mamun http://orcid.org/0000-0002-1535-8086

\section{REFERENCES}

1 GBD 2015 Risk Factors Collaborators. Global, regional, and national comparative risk assessment of 79 behavioural, environmental and occupational, and metabolic risks or clusters of risks, 1990-2015: a systematic analysis for the global burden of disease study 2015. Lancet 2016;388:1659-724.

2 Fisher NDL, Curfman G. Hypertension-A public health challenge of global proportions. JAMA 2018;320:1757-9.

3 World Health Organisation, World Health Day 2013. A global brief on hypertension: silent killer, global public health crisis. World Health Organization, 2013.

4 WHO Regional Office for South-East Asia. Noncommunicable diseases in the south-east Asia region, 2011: situation and response, 2011. Available: https://apps.who.int/iris/handle/10665/205578

5 Mohan V, Seedat YK, Pradeepa R. The rising burden of diabetes and hypertension in Southeast Asian and African regions: need for effective strategies for prevention and control in primary health care settings. Int J Hypertens 2013;2013:1-14.

6 Agho KE, Osuagwu UL, Ezeh OK, et al. Gender differences in factors associated with prehypertension and hypertension in Nepal: a nationwide survey. PLoS One 2018;13:e0203278:1-18.

7 Vaidya A, Pathak RP, Pandey MR. Prevalence of hypertension in Nepalese community triples in 25 years: a repeat cross-sectional study in rural Kathmandu. Indian Heart J 2012;64:128-31.

8 Hasan M, Sutradhar I, Akter T, et al. Prevalence and determinants of hypertension among adult population in Nepal: data from Nepal demographic and health survey 2016. PLoS One 2018;13:e0198028:1-14.

9 Sharma SK, Ghimire A, Radhakrishnan J, et al. Prevalence of hypertension, obesity, diabetes, and metabolic syndrome in Nepal. Int J Hypertens 2011;2011:1-9.

10 Shrestha UK, Singh DL, Bhattarai MD. The prevalence of hypertension and diabetes defined by fasting and 2-h plasma glucose criteria in urban Nepal. Diabet Med 2006;23:1130-5.

11 Mehta KD, Karki P, Lamsal M, et al. Hyperglycemia, glucose intolerance, hypertension and socioeconomic position in eastern Nepal. Southeast Asian J Trop Med Public Health 2011;42:197-207.

12 McLachlan CS, Sharma R, Khanal V, et al. Prevalence of hypertension in member countries of South Asian association for regional cooperation (SAARC). Medicine 2014;93:e74.

13 Habits D. Non Communicable Diseases Risk Factors : STEPS Survey Nepal 2013, 2013

14 Dhital SM, Karki A. Dealing with the burden of hypertension in Nepal : current status, challenges and health system issues. Reg Heal Forum 2013;17:44-52.

15 MOHP New ERA, ICF DHS Program. Nepal demographic and health survey 2016. 636, 2017

16 Whelton PK, Carey RM, Aronow WS, et al. 2017 ACC/AHA/AAPA/ ABC/ACPM/AGS/APhA/ASH/ASPC/NMA/PCNA guideline for the prevention, detection, evaluation, and management of high blood pressure in adults: a report of the American College of Cardiology/ American heart association Task force on clinical practice guidelines. Hypertension 2018;71.

17 Chalmers J. World health Organization-International Society of hypertension guidelines for the management of hypertension. Clin Exp Hypertens 1999;1999:1009-60.

18 Hou X. Urban - rural disparity of and untreated hypertension in China. Asia Pac J Public Heal 2008;20:159-69.

19 Ahmed S, Tariqujjaman M, Rahman MA, et al. Inequalities in the prevalence of undiagnosed hypertension among Bangladeshi adults: evidence from a nationwide survey. Int J Equity Health 2019;18:1-12.

20 World Health Organization. Nutrition Landacape information system: country profile indicators, 2010.

21 Wagstaff $A$. The bounds of the concentration index when the variable of interest is binary, with an application to immunization inequality. Health Econ 2005:14:429-32.

22 Wagstaff A, van Doorslaer E, Paci P. On the measurement of horizontal inequity in the delivery of health care. $J$ Health Econ 1991;10:169-205.

23 Kakwani N, Wagstaff A, van Doorslaer E. Socioeconomic inequalities in health: measurement, computation, and statistical inference. $J$ Econom 1997;77:87-103.
24 O'Donnell O, Van DE. Analyzing health equity using household survey data. Washington, 2008.

25 Koolman X, van Doorslaer E, van DE. On the interpretation of a concentration index of inequality. Health Econ 2004;13:649-56.

26 StataCorp. Stata statistical software. 13, 2013.

27 Shrestha S, Shrestha A, Koju RP, et al. Barriers and facilitators to treatment among patients with newly diagnosed hypertension in Nepal. Heart Asia 2018;10:e011047:1-7.

28 Mishra SR, Ghimire S, Shrestha N, et al. Socio-Economic inequalities in hypertension burden and cascade of services: nationwide crosssectional study in Nepal. J Hum Hypertens 2019;33:613-25.

29 Chataut J, Adhikari RK, Sinha NP. The prevalence of and risk factors for hypertension in adults living in central development region of Nepal. Kathmandu Univ Med J 2011;9:13-18.

$30 \mathrm{Kim}$ Y, Kong KA. Do hypertensive individuals who are aware of their disease follow lifestyle recommendations better than those who are not aware? PLoS One 2015;10:e0136858:1-13.

31 Karmacharya BM, Koju RP, LoGerfo JP, et al. Awareness, treatment and control of hypertension in Nepal: findings from the Dhulikhel heart study. Heart Asia 2017:9:1-8.

32 Mehata S, Shrestha N, Mehta R, et al. Prevalence, awareness, treatment and control of hypertension in Nepal: data from nationally representative population-based cross-sectional study. J Hypertens 2018;36:1680-8.

33 Singh RB, Fedacko J, Pella D, et al. Prevalence and risk factors for prehypertension and hypertension in five Indian cities. Acta Cardiol 2011;66:29-37.

34 Dhungana RR, Pandey AR, Bista B, et al. Prevalence and associated factors of hypertension: a community-based cross-sectional study in municipalities of Kathmandu, Nepal. Int J Hypertens 2016;2016:1-10.

35 Schmieder RE. Hypertoniebedingte endorganschäden. Dtsch Arztebl 2010;107:866-73.

36 Islam FMA, Bhuiyan A, Chakrabarti R, et al. Undiagnosed hypertension in a rural district in Bangladesh: the Bangladesh population-based diabetes and eye study (BPDES). J Hum Hypertens 2016;30:252-9.

37 Ataklte F, Erqou S, Kaptoge S, et al. Burden of undiagnosed hypertension in sub-Saharan Africa: a systematic review and metaanalysis. Hypertension 2015;65:291-8.

38 Numbeo. Health care index by country 2020, 2020. Available: https:// www.numbeo.com/health-care/rankings by country.jsp [Accessed 11 Jun 2020].

39 Zhou J, Fang S. Association between undiagnosed hypertension and health factors among middle-aged and elderly Chinese population. Int J Environ Res Public Health 2019;16:16071214.

40 Zallman L, Himmelstein DH, Woolhandler S, et al. Undiagnosed and uncontrolled hypertension and hyperlipidemia among immigrants in the US. J Immigr Minor Health 2013;15:858-65.

41 Choo EH, Ihm S-H, Lim S, et al. A simple screening score for undiagnosed hypertension. Int J Cardiol 2014;172:e465-7.

42 Abd Elaziz KM, Dewedar SA, Sabbour S, et al. Screening for hypertension among adults: community outreach in Cairo, Egypt. $J$ Public Health 2015;37:701-6.

43 Chor D, Pinho Ribeiro AL, Sá Carvalho M, et al. Prevalence, awareness, treatment and influence of socioeconomic variables on control of high blood pressure: results of the ELSA-Brasil study. PLoS One 2015;10:e0127382:1-14.

44 Mosca I, Kenny RA. Exploring differences in prevalence of diagnosed, measured and undiagnosed hypertension: the case of Ireland and the United States of America. Int J Public Health 2014;59:759-67.

45 Saito Y, Davarian S, Takahashi A, et al. Diagnosis and control of hypertension in the elderly populations of Japan and the United States. Int J Popul Stud 2015;1:19-28.

46 Marshall A, Nazroo J, Feeney K, et al. Comparison of hypertension healthcare outcomes among older people in the USA and England. $J$ Epidemiol Community Health 2016;70:264-70.

47 World Health Organization. Multisectoral action plan on the prevention and control of ncd (2014-2020), 2014. Available: https:// extranet.who.int/nutrition/gina/sites/default/files/NPL

48 Saito E, Gilmour S, Rahman MM, et al. Catastrophic household expenditure on health in Nepal: a cross-sectional survey. Bull World Health Organ 2014;92:760-7.

49 World Health Organization. Cardiovascular disease. Available: https:// www.who.int/cardiovascular_diseases/global-hearts/Global_hearts initiative/en/

50 Neupane D, McLachlan CS, Christensen B, et al. Community-Based intervention for blood pressure reduction in Nepal (COBIN trial): study protocol for a cluster-randomized controlled trial. Trials 2016;17:1-7.

51 Krishnan A, Finkelstein EA, Kallestrup P, et al. Cost-Effectiveness and budget impact of the community-based management of 
hypertension in Nepal study (COBIN): a retrospective analysis. Lancet Glob Health 2019;7:e1367-74.
52 Rakotz MK, Ewigman BG, Sarav M, et al. A technology-based quality innovation to identify undiagnosed hypertension among active primary care patients. Ann Fam Med 2014;12:352-8. 